\title{
Difficulties in initial algebra learning in Indonesia
}

\author{
Al Jupri • Paul Drijvers • \\ Marja van den Heuvel-Panhuizen
}

Received: 20 July 2012 / Revised: 25 May 2013 / Accepted: 9 December 2013 /

Published online: 1 February 2014

(C) Mathematics Education Research Group of Australasia, Inc. 2014

\begin{abstract}
Within mathematics curricula, algebra has been widely recognized as one of the most difficult topics, which leads to learning difficulties worldwide. In Indonesia, algebra performance is an important issue. In the Trends in International Mathematics and Science Study (TIMSS) 2007, Indonesian students' achievement in the algebra domain was significantly below the average student performance in other Southeast Asian countries such as Thailand, Malaysia, and Singapore. This fact gave rise to this study which aims to investigate Indonesian students' difficulties in algebra. In order to do so, a literature study was carried out on students' difficulties in initial algebra. Next, an individual written test on algebra tasks was administered, followed by interviews. A sample of 51 grade VII Indonesian students worked the written test, and 37 of them were interviewed afterwards. Data analysis revealed that mathematization, i.e., the ability to translate back and forth between the world of the problem situation and the world of mathematics and to reorganize the mathematical system itself, constituted the most frequently observed difficulty in both the written test and the interview data. Other observed difficulties concerned understanding algebraic expressions, applying arithmetic operations in numerical and algebraic expressions, understanding the different meanings of the equal sign, and understanding variables. The consequences of these findings on both task design and further research in algebra education are discussed.
\end{abstract}

Keywords Algebra · Difficulties · Indonesian students · Linear equations · Linear inequalities

\footnotetext{
A. Jupri $(\bowtie) \cdot$ P. Drijvers $\cdot$ M. van den Heuvel-Panhuizen

Freudenthal Institute for Science and Mathematics Education, Utrecht University, PO box 85170, 3508 AD Utrecht, The Netherlands e-mail: a.jupri@uu.nl

A. Jupri

Jurusan Pendidikan Matematika, FPMIPA, Universitas Pendidikan Indonesia, Jl. Dr. Setiabudhi No. 229, Bandung 40154, Indonesia
} 


\section{Introduction}

Algebra is a core topic within mathematics and in secondary school mathematics in particular. It is instrumental for achievements in other mathematical domains such as analytical geometry, calculus, and statistics. Algebra serves not only as a language for science, but also as a gateway to advanced mathematics and higher education. Furthermore, algebraic knowledge and skills are relevant in daily and professional life either directly or as a prerequisite (Katz 2007; Kendal and Stacey 2004). Therefore, successful algebra education is a precondition for achievements in mathematics education in general. Initial algebra education, which encompasses the students' first steps in this domain, is of course a crucial phase in algebra education (Van Amerom 2002).

Throughout the world, however, students experience difficulties in learning algebra (e.g., see Booth 1988; Drijvers 2003; Herscovics and Linchevski 1994; Kolovou 2011; Warren 2003). Moreover, algebra has been increasingly recognized as a subject that is not only hard to learn but also hard to teach well (Stacey et al. 2004; Watson 2009).

Although these difficulties in the learning and teaching of algebra are a worldwide phenomenon, the case of Indonesian algebra education deserves special attention. Indonesian students showed low scores in the recent TIMSS 2007 study: the Indonesian average score in the domain of algebra was 405, which is far below the international average of 500 (Gonzales et al. 2008). Moreover, Indonesian students' algebra performance was significantly lower than the scores of students from other Southeast Asian countries, such as Thailand, Malaysia, and Singapore, where students' average scores for algebra were 433, 454, and 579, and rankings were 29th, 20th, and 3rd, respectively.

This fact gives rise to the questions of why Indonesian students have such low algebra scores and why they seem to experience more difficulties in learning algebra than students in other countries. As an initial step to address these questions, this present study aims to investigate Indonesian students' difficulties in initial algebra.

\section{Theoretical background}

A closer look at Indonesian students' performance in initial algebra

Figure 1 shows an algebra task retrieved from the TIMSS 1999 study. It concerns connecting the corresponding linear equation to a given verbal statement. Only $37 \%$ of the Indonesian participants were able to solve it, which was significantly below the international average of $65 \%$ (Mullis et al. 2000). The TIMSS 2007 study shows similar result for Indonesian students solving the algebra task shown in Fig. 2 on

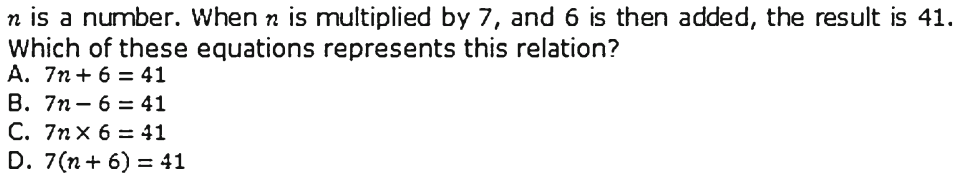

Fig. 1 TIMSS 1999 algebra task (Mullis et al. 2000) 


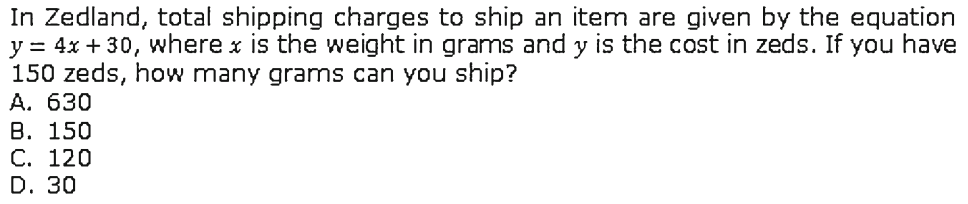

B. 150

C. 120

D. 30

Fig. 2 TIMSS 2007 algebra task (Mullis et al. 2008)

solving a linear equation in one variable presented in a context. This task was solved correctly by only $26 \%$ of Indonesian students which was significantly below the international average of $34 \%$ (Mullis et al. 2008).

As in many algebra curricula, linear equations in one variable are a central topic in the Indonesian initial algebra program (DEPDIKNAS 2006). The above two examples indicate that Indonesian students have serious difficulties with this topic. Therefore, in this study, we focus on linear equations in one variable, and the related linear inequalities. As many researchers (e.g., Herscovics and Linchevski 1994; Linchevski and Herscovics 1996; Pillay et al. 1998) have addressed linear equations in one variable to comprehend students' learning and thinking in the transition from arithmetic to algebra and students' capability to understand and use variables in particular, this seems an appropriate topic to further elaborate on.

Difficulties in initial algebra

What does existing research in initial algebra education tell us about students' learning difficulties? Some literature uses the term "difficulties" (e.g., Herscovics and Linchevski 1994; Warren 2003) or "conceptual difficulties" (e.g., Thomas and Tall 1991), while others speak of "errors" (e.g., Booth 1988). We decided to use the term "difficulties" as we consider errors as manifestations of the difficulties. The literature on initial algebra for 10-14 year-old students led us to identify five types of difficulties in initial algebra which we will now describe.

\section{Applying arithmetic operations}

Many studies show that 12-13 year-old students often fail to add or subtract like algebraic terms and sometimes detach symbolic expressions from the operations (e.g., Herscovics and Linchevski 1994; Linchevski 1995; Linchevski and Herscovics 1996). Also, students (11-14 year olds) misapply commutative as well as associative properties when carrying out subtractions or divisions (Booth 1988; Pillay et al. 1998; Warren 2003), and fail to use the distributive property of a multiplication over an addition (Booth 1988; Pillay et al. 1998). In our view, these difficulties reveal students' limited mastery of addition, subtraction, multiplication, and division; of applying the priority rules of arithmetic operations in calculations; and of using properties of numerical operations. We understand properties of numerical operations as commutative, associative, inverse, and distributive properties within both additive and multiplicative situations. All together, we summarize these issues as difficulties in applying arithmetic operations in both numerical and algebraic expressions and we abbreviate this type of difficulties as ARITH. 


\section{Understanding the notion of variable}

Concerning the literal symbols that are so crucial in algebra, research — carried out with 10-14 year-old students - reveals that students have difficulties to distinguish different roles of literal symbols such as placeholder, generalized number, unknown, or varying quantity (Booth 1988; Drijvers 2003; Linchevski and Herscovics 1996; Rosnick 1981; Usiskin 1988; Van Amerom 2002). As a placeholder, a literal symbol is seen as an empty "container" in which a numerical value can be stored or from which it can be retrieved. As an unknown, a literal symbol is used in a problem solving process in which the goal is to find a solution of an equation. As a generalized number, a literal symbol acts as a pattern generalizer symbolizing equivalence: all values substituted for the literal symbols will result in true statements, for instance $2 x+5 x=7 x$. As a varying quantity, a literal symbol is used in a functional relationship either as an input argument or as the output function value. We summarize issues with these roles as a category of difficulty in understanding the notion of variable, and we abbreviate this type of difficulties as VAR.

\section{Understanding algebraic expressions}

In addition to the different views on literal symbols, students also have to recognize that an algebraic expression, such as $x+10$, has a dual nature: it represents a calculation process as well as being an algebraic object in its own right (Drijvers 2003; Van Amerom 2002, 2003). In the literature, this is called the process-object duality (Sfard 1991); the inability to switch between the process and the object view is called the process-product obstacle (Thomas and Tall 1991). Other obstacles are identified, such as the inability to disentangle the order in which the algebraic expressions must be understood and processed, sometimes conflicting with the order of natural language. This is called the parsing obstacle. For example, in dealing with $12-5 x$, students may read from left to right as $12-5$ giving 7 , and consider the full expression to be equivalent to $7 x$; in dealing with $x+3$, students may read it as $x$ and 3 , and interpret this as $3 x$ (Thomas and Tall 1991). The expected answer obstacle is the incorrect expectation of having a numerical answer for an algebraic expression. This causes a related difficulty which is called the lack of closure obstacle, which is the discomfort from attempting to handle an algebraic expression which represents a process that cannot be carried out (Thomas and Tall 1991). One characteristic of an ability to manipulate algebraic expressions technically as well as with insight that causes difficulties in algebra is the gestalt view on algebraic expressions (Arcavi 1994, 2005). This concerns the ability to consider an algebraic expression as a whole, to recognize its global characteristics, and to foresee the effect of a manipulation strategy. According to Bokhove and Drijvers (2010), the gestalt view includes both pattern salience, i.e., the recognition of visual pattern in expressions and equations; and local salience, i.e., the attraction by local algebraic symbols, such as inequality signs and minus signs in inequalities or equations. The latter may lead to looking at symbols in isolation without taking the whole expressions into consideration. Furthermore, Bokhove and Drijvers perceive the gestalt view as enabling the learner to take strategic decisions about what to do next and to resist or succumb to the visual salience. We summarize these difficulties as a category of difficulty in understanding algebraic expressions, and we abbreviate these as AE. 


\section{Understanding the different meanings of the equal sign}

Another difficulty in initial algebra learning concerns the equal sign. In arithmetic, the equal sign often invites carrying out a calculation and writing down a numerical answer, whereas in algebra, it usually means "is algebraically equivalent to" (Filloy and Rojano 1989; Herscovics and Linchevski 1994; Ketterlin-Geller et al. 2007; Kieran 1981; Linchevski 1995; Pillay et al. 1998). With the former insight, students may interpret $2+3=\ldots$ as adding 2 and 3 to get the specific answer 5 and may not view $2+3=3+2 ; 2+3=1+4 ;$ or $5=2+3$ as possible solutions to the same task. The latter insight, however, is needed to understand equivalence, for example while rewriting $x+2=3 x+4$ as $x=3 x+2$. In this study, the difficulty in understanding the different meanings of the equal sign in arithmetic and algebra is abbreviated as EQS.

\section{Mathematization}

The final difficulty in initial algebra concerns mathematization, a core concept of the approach to teaching mathematics that is called realistic mathematics education (RME) (Freudenthal 1991; Treffers 1987). This mathematization has both horizontal and vertical mathematization aspects. The difficulty in horizontal mathematization concerns going from the world of real phenomena to the world of symbols and vice versa: in other words, to translate back and forth between the world of the problem situation and the world of mathematics (Treffers 1987; Van den Heuvel-Panhuizen 2000, 2003). These transitions are demanding for students and in particular 10-14 year-old students (Ketterlin-Geller et al. 2007; MacGregor and Stacey 1998; Van Amerom 2002, 2003; Warren 2003; Watson 2009). Activities of horizontal mathematization include, for instance, formulating a problem in a different way, discovering relations and regularities, and transferring a real-world problem to a mathematical problem or to a known mathematical model (De Lange 1987). These horizontal mathematization activities are in line with the first two problem solving heuristics proposed by Polya (1973), namely understanding the problem and devising a plan. The difficulty in vertical mathematization concerns dealing with the process of reorganization within the mathematical system itself, i.e., the process of moving within the symbolic world (Treffers 1987; Van den HeuvelPanhuizen 2000, 2003). Instances of vertical mathematization activities involve combining, integrating, formulating, and manipulating algebraic models while solving equations and inequalities; formulating a new mathematical concept; and proving regularities and generalizing (De Lange 1987; Treffers 1987; Van den Heuvel-Panhuizen 2000). In this study, we abbreviate this category of mathematization difficulties as MATH.

\section{Research question}

Table 1 provides an overview of the five categories as they emerged from the literature study. Of course, these five categories are not independent, but form a set of intertwined and related difficulties. The first three categories in particular might co-emerge, as they all concern algebraic meaning: the meaning of numerical operations, variables, and algebraic expressions, which are so significant in initial algebra. Whereas the ARITH, VAR, AE, and EQS categories come from the algebra domain, the mathematization category (MATH) is rooted in the theory of RME - which concerns mathematics 
Table 1 Overview of the five categories of difficulties in initial algebra learning

\section{ARITH}

1. Related operations: carrying out operations such as addition, subtraction, multiplication, and division of numbers or algebraic expressions

2. Related rules: following the rules of order of operations when dealing with numbers or algebraic expressions

3. Related properties: applying properties of numerical operations, i.e., commutative, associative, inverse, or distributive, when dealing with numbers or algebraic expressions

VAR

4. Roles of literal symbols: understanding literal symbols as placeholders, generalized numbers, unknowns, and varying quantities

$\mathrm{AE}$

5. Parsing obstacle: understand the order in which the algebraic expressions must be understood and processed, which may conflict with the order of natural language

6. Expected answer obstacle: an incorrect expectation to get a numerical answer for an algebraic expression

7. Lack of closure obstacle: the discomfort in attempting to handle an algebraic expression which represents a process that cannot be carried out

8. Lack of gestalt view: the inability to deal with algebraic expressions' visual salience, including both pattern salience, and local salience

EQS

9. Different meanings: the understanding of the different meanings of the equal sign in arithmetic (carrying out a calculation and writing down an answer) and in algebra ("is algebraically equivalent to")

MATH

10. Horizontal mathematization: the process of translating back and forth between the world of the problem situation and the world of mathematics

11. Vertical mathematization: the process of reorganization within the mathematical system or the process of moving within the symbolic world

education in general. As such, the MATH category complements the other categories of difficulties.

Taking the above types of difficulties which emerged from the literature study as a point of departure, the research question of this study is as follows:

What are Indonesian students' difficulties in initial algebra learning, particularly in solving linear equations in one variable and the related linear inequalities?

\section{Methods}

To address the research question, we conducted an explorative study in which an individual written test on algebra was administered, followed by student interviews on the written work.

\section{Sample}

The subjects of the study were 51 Indonesian students taken from two samples: 33 students from the 2011 grade VII cohort took part in the summer of 2011, and 18 
students from the 2012 grade VII cohort were involved in the summer of 2012. The two samples had the same characteristics: they finished grade VII (13/14 year-old), in which they had studied linear equations and inequalities in one variable in its first semester (DEPDIKNAS 2006). The students came from three different schools, one a public school, and the two others religious schools. As such, this school selection is representative for the Indonesian educational system, which consists of these two types of schools, and includes both urban and rural schools. In these three schools, the teaching of mathematics seems to be traditional-i.e., a teacher explains mathematical concepts with corresponding examples and gives exercises (mainly bare mathematics tasks), while students pay attention, take notes and do the exercises. This teaching approach is quite common in Indonesia (see, for instance, Johar 2010; Sembiring et al. 2008; Zulkardi 2002). Based on formative assessments as well as on a summative test at the end of the previous semester, the mathematics teachers in each of the schools selected the students to be included in the study, including high, medium, and low achievers in a balanced manner.

\section{Data collection}

In each school, data were collected by means of a written task and follow-up interviews. First, students were asked to solve a set of algebra tasks with paper and pencil individually for 30 to 40 minutes, and they were informed that their solutions would not be graded so that they would feel free to use their own solution methods. We planned to give 3-5 additional minutes in case students did not finish their work within the given time. However, all students seemed to have ample time to solve all the tasks. During the written test, students were not allowed to use calculators as they had not been allowed to use them during the learning process, in formative and in summative tests. The goal of this written test was to identify student difficulties with the algebra tasks.

Students had a break after the written test. This time was used to select students' written work based on a preliminary selection made through observation during the written test. In this way, the interviewer selected students for the additional individual interviews, which had as a goal to gather more detailed data on the occurring types of difficulties. Out of the 33 participating students who did the written test from the 2011 sample (10, 13, and 10 students from the first, second, and third school, respectively), 19 were interviewed afterwards. The number of interviewed students from the first, second, and third schools was six, eight, and five, respectively. In the 2012 sample, all 18 students who did the written test $(8,5$, and 5 students from the first, second, and third schools, respectively) were interviewed afterwards. The interviews were conducted and videotaped on the same day as the written test and took about 15-20 minutes each. The written test and interviews in the three schools were carried out on different days, i.e., during 1 day in each of the schools.

During the semistructured interviews, the students' written solutions of tasks were presented and they were encouraged to explain their reasoning. The interviewer did not intervene to get correct or incorrect solutions. As a guideline for carrying out the interviews, general starting questions and follow-up questions had been prepared to both focus on investigating students' difficulties and to allow flexibility during the interviews. The general interview questions included: Do you understand this problem? How did you solve this problem? Could you explain your solution? And how do you 
check whether your solution is correct or not? The follow-up questions included, for instance: Why did you make this step? What did you mean by this step? What is the next step? What does it mean? The former type of questions was used at the beginning of an interview, and the latter was used while the interview was taking place and depended on students' responses.

If a student did not solve one of the tasks, the interviewer asked whether he or she understood the task and then asked further questions depending on his or her reactions. For example, if a student did not solve a task, such as solve $4 x+7<15$, the interviewer would ask him or her to read the task aloud to identify whether the student understood if the task was about inequality or not. Next, the interviewer asked questions to the student based on his or her mistakes or misunderstandings. Although in the 2011 sample, there were two students who had left one item blank, the interviews revealed that this was caused by their inability to solve the task and not by a lack of time.

Tasks

The tasks used in this study, all algebra problems on linear equations and inequalities in one variable topic were taken from three sources. The first source consisted of Indonesian mathematics textbooks for students in grade VII, both governmental and private publishers' textbooks. The second source consisted of the TIMSS 2003 released items (IEA 2003) on algebra, particularly the linear equations and inequalities in one variable topic. The third source consisted of the set of PISA 2006 released items on algebra which in PISA is labeled as Change and Relationship (OECD 2006). An overview of the 16 tasks can be found in the Appendix 1.

For the 2011 sample, the 16 tasks were divided evenly into 4 sets, consisting of tasks $1-4,5-8,9-12$, and 13-16, respectively. The sets contained two bare and two contextual algebra tasks and were considered to be equivalent in terms of the degree of difficulty. Bare algebra tasks are tasks that are not related to contexts either within mathematics or other subjects (tasks $3,4,7,8,10,11,15$, and 16), whereas contextual algebra tasks are (tasks 1, 2, 5, 6, 9, 12, 13, and 14). Criteria for the tasks were that they should concern linear equations and inequalities, and because of the mathematization issue, the set should cover bare and contextual algebra tasks in a balanced manner. In the written test and interviews, the four sets were spread randomly so that each student was randomly assigned one of the four task sets.

For the 2012 sample, the same set of 5 tasks - namely tasks $5,7,11,13$, and 16 was used for all students. We decided to use the tasks on the topic of linear equations in one variable only as, based on the experience with the 2011 sample, this topic is representative as a means to reveal the five categories of difficulties in initial algebra. Because of the mathematization issue, the set covered bare algebra tasks (tasks 7, 11, and 16) and contextual algebra tasks (tasks 5 and 13) in a balanced manner. In order to serve students' differences, the set of tasks also included relatively easy and more difficult tasks (tasks 5, 7, and 11 being relatively easy, and the rest being more difficult).

Possible difficulties within the tasks

Before administering the written test and the interviews, we listed possible difficulties that students might encounter while solving the tasks. The bare algebra tasks might 
challenge students to deal with difficulties in the ARITH, VAR, AE, or EQS categories, whereas the contextual algebra tasks might challenge students to handle difficulties in all five categories. Table 2 summarizes the tasks and the categories of difficulties that students might encounter in the written test and in the interviews.

Table 2 shows that the difficulties in the ARITH category are challenged in all algebra tasks as they all require students to carry out calculational operations. Similarly, except for task 2 which only requires arithmetical operations, the VAR and the AE categories might emerge in all tasks as the variables and algebraic expressions play a crucial role. All together, the first three categories might frequently co-emerge. The EQS category of difficulty possibly emerges in tasks that explicitly use the equal sign, namely the tasks $3,7,9,10,11,15$, and 16 . The MATH category of difficulty might show up in contextual algebra tasks which require students to formulate mathematical forms, or in bare tasks that require students to "build" mathematics. Examples 1 and 2 illustrate the tick marks shown in Table 2.

\section{Example 1}

A bare algebra task used in the written test is to solve the following equation:

$$
\text { Solve for } x: 3(x-5)=2 x-7 \text {. }
$$

This equation, task 3 in the set, is categorized as a bare algebra task as it is not related to any context. This task might invite difficulties in ARITH, VAR, AE, and EQS categories. Concerning the ARITH category, the task requires the student to apply the distributive property, namely when expanding $3(x-5)$ into $3 x-15$; to apply an additive inverse property, e.g., when simplifying $3 x-15=2 x-7$ into $3 x=2 x-7+15$; and to subtract algebraic expressions, e.g., from $3 x-2 x=-7+15$ to $x=-7+15$. If a student was unable to apply these operations, she or he would encounter the ARITH category of difficulty. Concerning the VAR category, the task requires the student to understand the variable $x$ as an unknown to be found. Concerning the AE category, the task might invite the student to simplify, for instance, $3 x-15$, into $-12 x$, which suggests a misunderstanding of the meaning of the algebraic expression $3 x-15$ and which is categorized as a lack of closure obstacle (Thomas and Tall 1991); the task requires the student to visually recognize the brackets as an invitation to expand $3(x-5)$ before further calculations. Finally, the task might provoke the student to simplify $3 x-15=2 x-7$

Table 2 Tasks and possible categories of difficulties

\begin{tabular}{|c|c|c|c|c|c|c|c|c|c|c|c|c|c|c|c|c|}
\hline \multirow{2}{*}{$\begin{array}{l}\text { Category of } \\
\text { difficulties }\end{array}$} & \multicolumn{16}{|c|}{ Tasks } \\
\hline & 1 & 2 & 3 & 4 & 5 & 6 & 7 & 8 & 9 & 10 & 11 & 12 & 13 & 14 & 15 & 16 \\
\hline ARITH & $\checkmark$ & $\checkmark$ & $\checkmark$ & $\checkmark$ & $\checkmark$ & $\checkmark$ & $\checkmark$ & $\checkmark$ & $\checkmark$ & $\checkmark$ & $\checkmark$ & $\checkmark$ & $\checkmark$ & $\checkmark$ & $\checkmark$ & $\checkmark$ \\
\hline VAR & $\checkmark$ & & $\checkmark$ & $\checkmark$ & $\checkmark$ & $\checkmark$ & $\checkmark$ & $\checkmark$ & $\checkmark$ & $\checkmark$ & $\checkmark$ & $\checkmark$ & $\checkmark$ & $\checkmark$ & $\checkmark$ & $\checkmark$ \\
\hline $\mathrm{AE}$ & $\checkmark$ & & $\checkmark$ & $\checkmark$ & $\checkmark$ & $\checkmark$ & $\checkmark$ & $\checkmark$ & $\checkmark$ & $\checkmark$ & $\checkmark$ & $\checkmark$ & $\checkmark$ & $\checkmark$ & $\checkmark$ & $\checkmark$ \\
\hline EQS & & & $\checkmark$ & & & & $\checkmark$ & & $\checkmark$ & $\checkmark$ & $\checkmark$ & & & & $\checkmark$ & $\checkmark$ \\
\hline MATH & $\checkmark$ & $\checkmark$ & & & $\checkmark$ & $\checkmark$ & & & $\checkmark$ & & & $\checkmark$ & $\checkmark$ & $\checkmark$ & & \\
\hline
\end{tabular}


into $3 x=2 x-7+15=3 x-2 x=8$, i.e., misunderstanding the meaning of the equal sign as an algebraic equivalence which falls into the EQS category.

\section{Example 2}

A contextual algebra task used in the written test is to solve the following:

The sum of three consecutive positive integers is not greater than 63 . Find boundaries for each of the numbers.

This task, task 14 in the set, is categorized as a contextual algebra task as it is related to a mathematical context, namely the challenge to find boundaries for each of the numbers that satisfies the statement in the task. Possible difficulties in this task include the MATH, VAR, ARITH, and AE categories. Concerning the MATH category, the task requires the student to translate the word problem into a mathematical form, such as $x+(x+1)+(x+2) \leq 63$ in which $x,(x+1)$ and $(x+2)$, represent three unknown consecutive integers. The student might encounter difficulties in translating the word problem into the mathematical form, namely the inequality. This difficulty includes the difficulty to use variables, as varying quantities, to represent three consecutive integers which fall into the VAR category. With regard to the ARITH category, if a student is able to get $x+(x+1)+(x+2) \leq 63$, then the inequality requires to be rewritten into $3 x+3 \leq 63$ which is the application of the associative property of addition. Finally, the task might invite the student to simplify $x+(x+1)+(x+2)$ into $6 x$, i.e., experiencing a lack of closure obstacle (Thomas and Tall 1991), which is included as the AE category.

\section{Analysis of the student data}

The data of the study include student worksheets of the written test, interview video registrations (audio-video data of interviews), and interview field notes. A unit of analysis or case in this study is a student's written work on one single test item or a video clip which covers the interview on one single task. A case may reveal more than one category of difficulty and a particular difficulty may include more than one subcategory. Therefore, the total number of difficulties may exceed the number of cases.

For the 2011 sample, the data were analyzed in three steps with the help of software for qualitative data analysis - in our case Atlas.ti. First, the data were organized and clipped into cases which serve as units of analysis. Next, the categorization described in subsection 2.2 (see Table 1) was used as an initial lens, and was elaborated through its use in the preliminary analysis. In this way, an analytical framework was developed in a bottom-up way. Finally, this framework was applied once more through coding the dataset.

For the data from the 2012 sample, the framework developed in the 2011 analysis was applied through coding the dataset. To establish interobserver reliability, a second coder who was a mathematics educator not involved in this study analyzed $20 \%$ of the cases of both the 2011 and the 2012 sample after being given an explanation about the framework and the code book manual for data analysis. With a Cohen's Kappa of 0.77, the agreement between the first author and the second coder at the level of subcategorization was found to be substantial (Landis and Koch 1977). 
Framework for analyzing student responses

In this section, we describe the analytical framework which elaborates each of the five categories identified in subsection 2.2. The corresponding examples within Tables 3, 4, 5,6 , and 7 illustrate the categorizations.

\section{Difficulties in the ARITH category}

Table 3 shows the framework for the ARITH category. Students' capabilities in carrying out arithmetic operations (related operations) were grouped into two subcategories as follows: mistakes in carrying out operations on numbers, and mistakes in carrying out operations on algebraic expressions. Concerning the priority rules of arithmetic operations (related rules), students made mistakes in applying these either in numerical or in algebraic expressions. Concerning students' mastery in applying properties of numerical operations (related properties), we categorized students' mistakes into three subcategories as follows: (1) misapplication of the commutative property in calculating a division in numerical expressions, (2) misuse of the distributive property of a multiplication over an addition, and (3) an improper use of the additive inverse property in solving an equation.

\section{Difficulties in the VAR category}

Table 4 shows the framework for the VAR category. Concerning understanding the meaning of variables, students made mistakes in interpreting a literal symbol as having one single value rather than more than one in an inequality, and in substituting a particular number in an equation.

Table 3 The ARITH category

\begin{tabular}{lll}
\hline Difficulties in the & Subcategory & Examples \\
ARITH category &
\end{tabular}

\begin{tabular}{lll}
\hline 1. Related operations & (i) A student makes mistakes when carrying out addition, & $\bullet 70 / 2=140$ \\
subtraction, multiplication, or division of numbers & $\bullet n=140 / 70=20$ \\
& (ii) A student makes mistakes when carrying out addition, & $\bullet 2 x+x=2 x^{2}$ \\
subtraction, multiplication, or division of algebraic & $\bullet 2 x+3 x=5 x^{2}$ \\
expressions (difficulties in combining like terms) & \\
2. Related rules & (i) A student does not follow the rules of order of & $\bullet 17-3+5=17-8$ \\
arithmetical operations in numerical or in & $\bullet 6 x+2 x-8+2=8 x-10$ \\
algebraic expressions & \\
3. Related properties & (i) A student misapplies a commutative property in & $\bullet p=70 / 140 \Rightarrow p=2$. \\
& calculating a division in numerical expressions & $\bullet 70 / p=140 \Rightarrow p=2$. \\
(ii) A student misuses a distributive property of a & $\bullet 2(2 x+5)=4 x+5$ \\
multiplication over an addition in algebraic expressions & \\
(iii) A student does not use an additive or & $\bullet 5 x+2=10-3 x \Rightarrow$ \\
multiplicative inverse in solving an equation & $5 x-3 x=10+2$ \\
&
\end{tabular}


Table 4 The VAR category

Difficulties in the Subcategory $\quad$ Examples VAR category

4. Roles of literal (i) A student interprets symbol has only a symbols

(i) A student interprets symbol has only a
single rather than more than one value (variables as a varying quantity.)

(ii) A student substitutes a literal symbol in an equation with a particular value and the result is incorrect (variable as an unknown)
- Solution for $4 x+7<15$ is

$x=7+4=11+4=15$

- A substitution value in the task $3 x+5=17-x$. In the task, each of the terms $3 x$ and $x$ is replaced by 12

\section{Difficulties in the AE category}

Table 5 shows the framework for the AE category. Concerning obstacles related to algebraic expressions, students encountered the parsing obstacle, the expected answer obstacle, and the lack of closure obstacle.

Concerning the gestalt view on algebraic expressions, students ignored local salience in an algebraic expression, such as neglecting the inequality sign while solving $5 x+2 \geq 10-3 x$ and ignored pattern salience aspects, such as neglecting an algebraic expression of two terms within a bracket while expanding $2(2 x+5)$ into $4 x+5$.

\section{Difficulties in the EQS category}

Table 6 shows the framework for the EQS category. This category includes two different mistakes where students do not understand the meaning of the equal sign as

Table 5 The AE category

\begin{tabular}{ll}
\hline $\begin{array}{l}\text { Difficulties in } \\
\text { the AE category }\end{array}$ & Subcategory
\end{tabular}

5. Parsing obstacle (i) A student experiences a conflict between the order $\cdot 17-8 x=9 x$

in natural language and in algebraic language

6. Expected answer (i) A student expects to have a numerical answer obstacle for an algebraic expression

7. Lack of closure obstacle

8. Lack of gestalt view (i) A student adds or subtracts algebraic terms and numbers to get an algebraic term within an algebraic expression

(i) A student ignores local salience in an algebraic expression, such as the inequality sign $<$, the variable $x$, positive or a negative sign of an algebraic term

(ii) A student ignores pattern salience in an algebraic expression, such as an algebraic expression with two term and within a bracket
- $x+9=9 x$

- From $4 x+7<15$ to

$x=7+4=11+4=15$

- $15+2 x=17$

- $2 x+3=5 x$

- $2 x-1=x$

- From $4 x+7<15$ to $x-7+4=11+4=15$

- $4 x+7=11 x$

- $5 x+2=10-3 x \Rightarrow 5 x-3 x=10+2$

- $x+5=5 x$

- $2(2 x+5)=4 x+5$ 
Table 6 The EQS category

\begin{tabular}{lll}
\hline $\begin{array}{l}\text { Difficulties in the } \\
\text { EQS category }\end{array}$ & Subcategory & Examples \\
\hline $\begin{array}{l}\text { 9. The different } \\
\text { meanings of the } \\
\text { equal sign }\end{array}$ & $\begin{array}{l}\text { (i) A student does not understand the meaning } \\
\text { of the equal sign as algebraic equivalence, } \\
\text { such as the student makes a notational error } \\
\text { as a result of a combination of operations }\end{array}$ & $\begin{array}{l}\bullet x=7+4=11+4=15 \\
\text { (ii) A student does not understand the meaning } \\
\text { of the equal sign as algebraic equivalence, } \\
\text { such as the student ignores the equal sign } \\
\text { and applies an incorrect simplification on } \\
\text { algebraic expression }\end{array}$
\end{tabular}

an algebraic equivalence. First, students made a notational error as a result of a combination of operations - which is called a "running" statements error (Jones and

Table 7 The MATH category

Difficulties in the Subcategory
MATH category

\section{Horizontal mathematization \\ (i) A student mistranslates words or phrases into mathematical notations}

11. Vertical mathematization

(ii) A student fails to formulate an equation or an inequality from the given (word) problem

(iii) A student encounters a difficulty in interpreting a mathematical concept and a pattern, in substituting information into a formula and in using a formula

(i) A student encounters difficulties in combining, in integrating, or in using information either given in the task or given as a result of calculation in solving symbolic algebra problems

(ii) A student uses an arithmetical method rather than an algebraic method to solve symbolic algebra problems

(iii) A student encounters a difficulty in manipulating symbol when solving symbolic algebra problems

(iv) A student misapplies equation solving when simplifying algebraic expressions •"is not greater than" is mistranslated into $\geq$

-Reformulating an equation

-Reformulating an equality

- a cube is misinterpreted as a square

-Recognizing a pattern.

-Misusing a formula

$x-y=5 \Rightarrow 5=x+y$ and
$\frac{x}{2}=3 \Rightarrow x=2 \times 3=6$

- $4(x+5)=80 \Rightarrow 80: 4-5=20-5=15$

- $4(x+5)=80 \Rightarrow 4 x+20=80$

- $(3 x-4)+(3 x-4)+(x+1)+(x+1)$

$=3 x-4+3 x-4+x+1+x+1$

$=8 x-8+2$.

$=8 x-8+2-2$.

$=8 x-8$

$=8 x-8+8$

$=8 x$. 
Pratt 2012; Saenz-Ludlow and Walgamuth 1998). Second, students ignored the equal sign and applied an incorrect simplification on algebraic expressions. For example, they changed $3(x-5)=2 x-7$ into $3(3 x+12)=3(15 x)$, i.e., added $x$ and $2 x$ to be $3 x$, and added 5 and 7 to be 12 (ignoring the negative signs of -5 and -7 ), and next changed $3 x+12$ into $15 x$.

\section{Difficulties in the MATH category}

Table 7, finally, shows the framework for the MATH category. Concerning horizontal mathematization difficulties, students encountered difficulties in translating phrases into mathematical notations, in reformulating the given (word) task into a mathematical form, in interpreting mathematical concepts and patterns, in substituting information into a mathematical formula, and in using a given formula.

Concerning vertical mathematization difficulties, students encountered difficulties in combining as well as integrating information either given in the task or given as a result of calculations while solving symbolic algebra tasks; in using the algebraic method; in manipulating symbols when solving symbolic algebra tasks; and in applying equation solving methods.

\section{Results}

Table 8 summarizes the number of tasks done by students in the written test and the percentages of correct responses. Table 9 provides the same data for the interviews, and the two tables show little difference. All students solved tasks 1 and 15 correctly, maybe because these tasks can be solved by using arithmetical calculations only. In contrast, no student was able to solve tasks $4,9,12$, and 14 . This seems to be caused by two reasons. First, the tasks 4, 12, and 14 concern (relatively complex) linear inequalities and these last 2 tasks require students to reformulate inequalities from contexts. Second, students involved in this study were 13-14 years old, whereas task 9 (from the PISA 2006 study) was intended for 15-16-year-old students.

To see difficulties encountered by students within each of the five categories, Table 10 summarizes the result of the data analysis from both the written test and the interviews in terms of the framework. In total, the two samples provide 222 cases (33 students $\times 4$ tasks +18 students $\times 5$ tasks, see column 3 ) from the written test, in which 166 cases $(19$ students $\times 4$ tasks +18 students $\times 5$ tasks $)$ provide extra information from

Table 8 Written test: Numbers of task done by students and percentage solved correctly

\begin{tabular}{lllllllllllllllll}
\hline Task & 1 & 2 & 3 & 4 & 5 & 6 & 7 & 8 & 9 & 10 & 11 & 12 & 13 & 14 & 15 & 16 \\
\hline $\mathrm{N}$ & 5 & 5 & 5 & 5 & 24 & 6 & 24 & 6 & 12 & 12 & 30 & 12 & 28 & 10 & 10 & 28 \\
$\mathrm{NC}$ & 5 & 3 & 1 & 0 & 4 & 4 & 11 & 2 & 0 & 9 & 23 & 0 & 7 & 0 & 10 & 12 \\
$\% \mathrm{C}$ & 100 & 60 & 20 & 0 & 17 & 67 & 46 & 33 & 0 & 75 & 77 & 0 & 25 & 0 & 100 & 43
\end{tabular}

$N$ number of students who have done a task, $N C$ number of students who solved a task correctly, \%C percentage correct 
Table 9 Interviews: Numbers of task addressed and solved correctly

\begin{tabular}{lllllllllllllllll}
\hline Task & 1 & 2 & 3 & 4 & 5 & 6 & 7 & 8 & 9 & 10 & 11 & 12 & 13 & 14 & 15 & 16 \\
\hline $\mathrm{N}$ & 5 & 5 & 5 & 5 & 23 & 5 & 23 & 5 & 6 & 6 & 24 & 6 & 21 & 3 & 3 & 21 \\
$\mathrm{NC}$ & 5 & 3 & 1 & 0 & 4 & 3 & 10 & 1 & 0 & 4 & 18 & 0 & 7 & 0 & 3 & 10 \\
$\%$ & 100 & 60 & 20 & 0 & 17 & 60 & 44 & 20 & 0 & 67 & 75 & 0 & 33 & 0 & 100 & 48 \\
\hline
\end{tabular}

$N$ number of students who have done a task, $N C$ number of students who solved a task correctly, $\% \mathrm{C}$ percentage correct

the interviews. As one case may have more than one category of difficulty, and a particular difficulty may include more than one subcategory, the number of codes may exceed the number of cases. An elaboration of Table 10 at the task level can be found in Appendix 2.

\section{Findings from the written test}

We now discuss the findings presented in Table 10 in more detail. The column "Difficulties in written tests by all students" shows the observed difficulty in the cases from the written test data. It reveals that the mathematization category (MATH) caused the most frequent difficulties, namely in 70 (32\%) out of 222 cases. Subcategory 10(ii) on reformulating equations or inequalities was the most frequent one, followed by the interpretation of mathematical concepts, patterns, and formulas (10(iii)); mistranslations of phrases into mathematical notations (10(i)); difficulties in manipulating symbols (11(iii)), applying algebraic methods to solve symbolic algebra tasks (11(ii)); and a misapplication of equation solving (11(iv)). Similar results occurred in the written test data of the interviewed students (see the fourth column), namely 48 (29\%) out of 166 cases. In short, written test data show that mathematization difficulties were frequent and that the problems concerned horizontal mathematization in particular.

The second category in frequency concerned difficulties in applying arithmetic operations in both numerical and algebraic expressions (the ARITH category), with 36 (16\%) out of 222 cases. The observations were divided over subcategories as follows: using an additive inverse property in solving an equation (3(iii)), using a distributive property of a multiplication over an addition in algebraic expressions (3(ii)), carrying out arithmetical operations in numerical expressions (1(i)), carrying out arithmetical operations in algebraic expressions (1(ii)), following priority rules of arithmetical operations (2(i)), and misapplying the commutative property in numerical expressions (3(i)). This result was similar to the written test data of the interviewed students.

The third category in frequency concerned difficulties in algebraic expressions (the AE category), with 32 (14\%) out of 222 cases. In this category, there was a small difference with the written test data of the interviewed students, with $19(11 \%)$ out of 166 cases. The observations were divided over subcategories as follows: the local salience of algebraic expressions (8(i)), the pattern salience of algebraic expressions (8(ii)), the parsing obstacle (5(i)), the lack of closure obstacle (7(i)), and the expected answer obstacle (6(i)). Apparently, algebraic expressions are difficult for the students: all subcategories are involved and no subcategory was dominant. The categories of difficulties on the equal sign (EQS) and the notion of variable (VAR) were observed less frequently. 
Table 10 Observed difficulties in algebra: category frequencies and percentages

\begin{tabular}{llll}
\hline Category Subcategory & $\begin{array}{l}\text { Difficulties in written } \\
\text { test by all students } \\
\text { (total } 33 \times 4+18 \times 5= \\
222 \text { cases) }\end{array}$ & $\begin{array}{l}\text { Difficulties in written } \\
\text { test by interviewed } \\
\text { students (total } 19 \times 4+ \\
18 \times 5=166 \text { cases })\end{array}$ & $\begin{array}{l}\text { Difficulties by interviewed } \\
\text { students in written test and } \\
\text { during interviews (total } \\
19 \times 4+18 \times 5=166 \text { cases) }\end{array}$ \\
\hline
\end{tabular}

\begin{tabular}{|c|c|c|c|c|}
\hline \multicolumn{5}{|c|}{ ARITH } \\
\hline \multirow[t]{2}{*}{1} & (i) & 6 & 4 & 4 \\
\hline & (ii) & 4 & 4 & 7 \\
\hline 2 & (i) & 4 & 1 & 1 \\
\hline \multirow[t]{4}{*}{3} & (i) & 3 & 1 & 1 \\
\hline & (ii) & 6 & 5 & 10 \\
\hline & (iii) & 13 & 13 & 15 \\
\hline & Total & $36(16 \%)$ & $28(17 \%)$ & $38(23 \%)$ \\
\hline \multicolumn{5}{|l|}{ VAR } \\
\hline \multirow[t]{3}{*}{4} & (i) & 2 & 2 & 3 \\
\hline & (ii) & 3 & 2 & 17 \\
\hline & Total & $5(2 \%)$ & $4(2 \%)$ & $20(12 \%)$ \\
\hline \multicolumn{5}{|l|}{$\mathrm{AE}$} \\
\hline 5 & (i) & 6 & 4 & 11 \\
\hline 6 & (i) & 4 & 4 & 8 \\
\hline 7 & (i) & 5 & 1 & 5 \\
\hline \multirow[t]{3}{*}{8} & (i) & 11 & 6 & 11 \\
\hline & (ii) & 6 & 4 & 17 \\
\hline & Total & $32(14 \%)$ & $19(11 \%)$ & $52(31 \%)$ \\
\hline \multicolumn{5}{|l|}{ EQS } \\
\hline \multirow[t]{3}{*}{9} & (i) & 16 & 16 & 17 \\
\hline & (ii) & 0 & 0 & 3 \\
\hline & Total & $16(7 \%)$ & $16(10 \%)$ & $20(12 \%)$ \\
\hline \multicolumn{5}{|c|}{ MATH } \\
\hline \multirow[t]{3}{*}{10} & (i) & 4 & 2 & 8 \\
\hline & (ii) & 55 & 40 & 42 \\
\hline & (iii) & 6 & 2 & 4 \\
\hline \multirow[t]{5}{*}{11} & (i) & 0 & 0 & 1 \\
\hline & (ii) & 1 & 1 & 2 \\
\hline & (iii) & 3 & 3 & 5 \\
\hline & (iv) & 1 & 0 & 0 \\
\hline & Total & $70(32 \%)$ & $48(29 \%)$ & $62(37 \%)$ \\
\hline
\end{tabular}

To illustrate these results, we present two examples of a student's written work and the way in which we applied the framework. Figure 3 shows the first example on task 12 . The student exhibited two categories of difficulties, coded as MATH and ARITH categories. For the former, the student could not formulate the word problem into the inequality $12(x+2) \leq$ 180 ; instead, he reformulated it as $(2+x)=180$. This is categorized as MATH, and as a problem of setting up an inequality from the given word problem in particular (subcategory 10(ii)). This difficulty seems to be caused by the inability to use the number of the cube's 
Sebuah kubus dengan panjang rusuk $(x+2)$ cm akan dibuat. Jika rangka kubus tersebut akan dibuat dari seutas kawat yang panjangnya tidak lebih dari $180 \mathrm{~cm}$, tentukan batas-batas panjang rusuk kubus tersebut!

Penyelesaian:

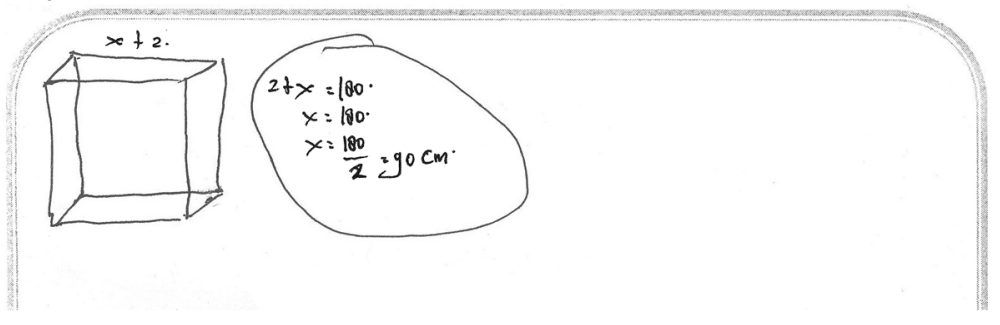

Translation:

A cube with the edge $(x+2) \mathrm{cm}$ will be made. If the skeleton of the cube is made from a wire that is not longer than $180 \mathrm{~cm}$, find the boundaries of the edge.

Solution:

Fig. 3 A student's written work on task 12 with MATH and ARITH difficulties

edges to translate the word phrase "is not longer than" and to integrate this into the inequality $12(x+2) \leq 180$. In addition, the student seemed to overlook the task of finding the boundaries of the edge. This indicates that the student lacked understanding of the problem as a whole as the first problem solving heuristic (Polya 1973). For the ARITH category, if $(2+x)=180$ were a correct reformulation of the given task, the next step should have been $x=180-2=178$ instead of $x=\frac{180}{2}=90$. This mistake is categorized in the ARITH category, in the subcategory of an incorrect use of the additive inverse property in solving an equation (3(iii)). As indicated in Table 2, beforehand, we noticed that task 12 might invite difficulties in the ARITH, VAR, AE, and MATH categories. In this observation, however, only the ARITH and the MATH categories of difficulties were identified. There are two cases in this student's work that seem to be included within the VAR and AE categories. Although rewriting $x+2$ as $2+x$ is correct, it may suggest that the student was uncomfortable with operating the variable $x$ first and 2 afterwards, probably because he is more familiar with 2 than with $x$. This suggests a VAR issue. Second, the student's rewriting $2+x=180$ as $x=180$ (which is strange, as the number 2 is missed in this step), and to $x=\frac{180}{2}=90$ might suggest that he interpreted $(2+x)$ as $2 x$ (the parsing obstacle from the AE category). However, these two interpretations were not explicitly written in the student work, and therefore, the VAR and AE codes were not assigned. This shows that the analysis of written work is limited, which is why additional interview data were needed in the analysis.

The second example concerns task 11 shown in Fig. 4. The ARITH category of difficulty that can be identified from the student's written work concerns the step from $x-9=13$ to $13=x+9$. In this step, the student seems to improperly use an inverse property of addition (subcategory 3(iii)), i.e., by changing -9 into +9 as if this number moves to the other side of the equation. If this is the case, he should also change the signs of $x$ and 13, yet he did not do so. This might be a notational error, but we have no information on that. Therefore, we coded this as the ARITH category and in the subcategory 3(iii). The AE category of difficulty that can be identified from Fig. 4 includes $x+9=9 x$ and $13-9 x=4$. Concerning the former, the student might read $x+9$ as $x$ and 9 , and might interpret them as $9 x$ and vice versa. With regard to the latter, the student might read $13-9 x$ as $13-9$ giving 
4, and might interpret the full expression as $4 x$. Both mistakes are considered parsing obstacles as the student encountered a conflict between the order in natural language and the order in algebraic language (subcategory 5(i)). Beforehand, we thought that this task might invite difficulties in the ARITH, VAR, AE, and EQS categories (see Table 2). In the written work, however, only the ARITH and AE categories were observed. Even if one argued that the student encountered an EQS category of difficulty, namely from the step $13=9 x$ to " $=13-9 x$," we perceive this as an application of an additive inverse property which falls into the ARITH category. In addition, the difficulty in the AE category might also be caused by the difficulty in the VAR category (which is inherent within the understanding of algebraic expressions). Overall, it may be due to these interpretations that the frequencies of the EQS and VAR categories are so low.

Findings from the interviews

Table 10's columns on "Difficulties in written test" for all students and for the students who were interviewed show little differences. The final column on "Difficulties in interviews," however, confirms the findings from the written test: mathematization, algebraic expression, and the arithmetic operation categories are the most frequently observed, but their relative frequencies have increased. This suggests that the interviews do offer additional information.

Concerning the MATH category, again, the subcategory of reformulating equations or inequalities (10(ii)) was the most frequent one. As this subcategory is in line with the first two problem solving heuristics proposed by Polya (1973), namely understanding the problem and devising a plan, it seems that solving contextual (word) algebra tasks is a serious problem for Indonesian students. Although the Indonesian mathematics curriculum suggests emphasizing problem solving activities and solving contextual mathematics tasks in particular (DEPDIKNAS 2006), we observed in both the governmental and private publishers textbooks (e.g., Adinawan and Sugijono 2007; Budhi 2007; Nuharini and Wahyuni 2008; Wagiyo et al. 2008) that contextual tasks appear only at the beginning of chapters as motivational tasks and at the end of chapters as applications. Thus, this fact might contribute to this result.

Tentukan nilai $x$ pada persamaan berikut:

$$
x-9=13 .
$$

Penyelesaian:

$$
\begin{aligned}
& x-9=13 \\
& 13=x+9 \\
& 13=9 x \\
& =13-9 x \\
& =4 x
\end{aligned}
$$

Translation:

- Solve for $x: x-9=13$

- Solution

Fig. 4 A student's written work on task 11 with ARITH and AE difficulties 
The difficulty in the AE category might be caused by when the interviews took place. Based on the curriculum, the linear equations and inequalities in one variable topic were taught in the first semester of grade VII (DEPDIKNAS 2006). This study, however, was conducted during the second semester which focused on geometry topics. We conjecture, therefore, that the students had forgotten the linear equations and inequalities in one variable concepts and as such made mistakes, particularly in this category. This suggests that the students' learning processes may lack the conceptual understanding that might have prevented them from forgetting. The subcategory of the gestalt view on pattern salience was the most frequent, followed subsequently by the gestalt view on local salience, the parsing obstacle, expected answer obstacle, and the lack of closure obstacle. From these results, it seems that students had only learned the algebra algorithmically without a conceptual understanding of algebraic expressions. For instance, we observed that students made mistakes simplifying $17-8 x$ into $9 x$ (parsing obstacle) and simplifying $2 x+3$ into $5 x$ (lack of closure obstacle).

With regard to difficulties in the ARITH category, these might be caused by the fact that the arithmetic operations now should be carried out in the context of algebra which relates to the understanding of variables and algebraic expressions. For example, in simplifying $2 x+x$ into $2 x^{2}$, the mistake probably occurred because students might not understand the meaning of the variable in the term of $2 x$ and might not understand the algebraic expression $2 x+x$ which requires to add rather than to multiply variables.

Concerning the EQS category, the low frequency of its occurrence was surprising. Beforehand, we expected that this category would frequently occur for tasks that explicitly use the equal sign. However, we observed that this was not always the case. In fact, the EQS difficulty also appeared in the tasks that require students to reformulate equations as a consequence of combining operations. An explanation for the low frequencies could be that this difficulty is fairly subtle, relates to other difficulties, and does not occur at the concreteobservational level. Moreover, this could also be caused by the number of tasks that have the scope for the EQS category is less frequent as compared to other tasks (see Table 2).

Finally, the VAR category was expected to co-occur with the AE category. However, the results were different. The low frequency of this category might be because this type of difficulty could be inherent within the AE and the ARITH categories.

To illustrate these results, we present two examples from student interviews and the way in which we applied the framework. Fig. 5 shows the task and the interview setting of the first example.

By observing this student's written work, it is difficult to determine the difficulties that the student encountered. The following interview transcript sheds new light on the student's thinking.

I: What does it mean with this problem?

$\mathrm{S}$ : [Reads the problem and her written work solution, as well as pointing the stages 1-3 and the corresponding number of squares].

I: How did you determine the number of squares for stage 4 ?

S: [Again, she reads her written work solution that the number of squares for the fourth stage is nine]

I: Why? [Why is the number of squares for the fourth stage nine?] 


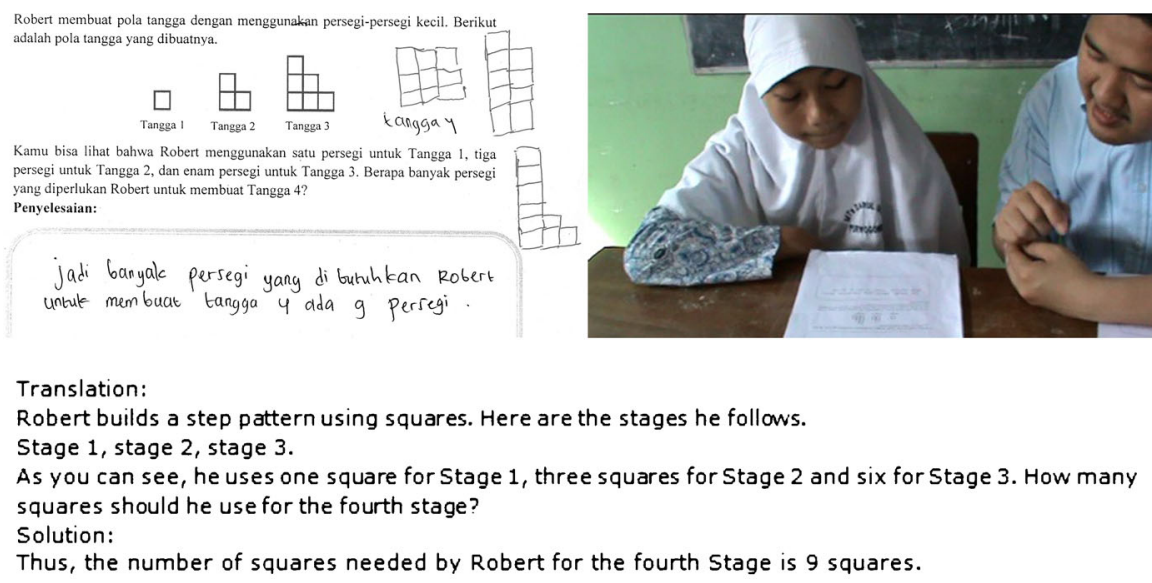

Fig. 5 A student interview on task 2 revealing MATH difficulty

S: Because $6+3=9$ [Six means the number of squares in stage 3 , and three means the number of squares in stage 2]. Because the difference of the number of these [the number of squares in stage 2 and 3] is 3 [She did not consider the difference of the number of squares between stages 1 and 2]

I: Are you sure the difference [of the number of squares between stages] is three?

S: Yes!

I: Show me that the difference is three.

After showing the difference between the number of squares of stages 3 and 2, she draws the figure of stage 4 . She draws three different figures, and the number of squares for stage 4 is nine.

The interview transcript reveals that the student encountered difficulties in the MATH category, as she could not identify the pattern of the differences of the number of squares between the stages (subcategory 10(iii)).

The second example concerns task 4. Figure 6 shows one student's written work. Although the student drew an inappropriate conclusion at the end of her solution, namely "So, the value of $x$ that satisfies the inequality is 2 ," the written solution is true. Noticing the crossed out part, namely from $4 x+7<15$ to $11 x<15$, it seems that the student encountered the AE category of difficulty and the lack of closure obstacle in particular (subcategory 7(i)), i.e., she added the algebraic term $4 x$ and the number 7 to get $11 x$. However, as this part was crossed out and the student's solution is true, we did not assign this an AE category.

The following interview transcript again provides additional information.

I: Please, let me know how you solved this problem.

$\mathrm{S}$ : This is about inequality!

I: It is alright, please let me know what you did!

$\mathrm{S}$ : [Reads her written solution $4 x+7<15,4 x<15-7,4 x<8, x<8: 4, x<2$

I: What does $4 x$ mean: does it mean $4+x$ or 4 times $x$ ? [As in the crossed out part of the written solution she added $4 x$ and 7 to get $11 x$, the interviewer asks the meaning of $4 x$ ] 
S: $4+x$.

I: So, $4 x$ is equal to $4+x$ [write $4 x=4+x$ ]. Is it what you mean?

S: Yes!

I: What is the meaning of $4 x^{2}$

S: 4 times $x$.

I: What is the result of $3+x$ ?

S: $3 x$

I: What is the result of 3 times $x$ [write $3 x]$ ?

S: $3 x^{2}$

The transcript reveals that the student encountered the AE category of difficulty and the parsing obstacle in particular (subcategory 5(i)), i.e., she understood that $4 x$ means $4+x$ (conflicting between the order of natural and algebraic languages). This difficulty might cause the lack of closure difficulty as indicated in the analysis of the written work only. Furthermore, she calculated, for instance, 4 times $x$ to be equal to $4 x^{2}$, which falls into an ARITH category of difficulty and the inability to carry out multiplication of algebraic expressions (subcategory 1(ii)).

\section{Discussion and conclusions}

Overview of student difficulties in initial algebra

The research question in this study concerns Indonesian students' difficulties in initial algebra learning, and in solving linear equations and inequalities in particular. From this study's data, we conclude that the students' most important difficulties in initial algebra concern mathematization (MATH), the understanding of algebraic expressions (AE), applying arithmetic operations in numerical and algebraic expressions (ARITH), understanding the different meanings of the equal sign (EQS), and understanding the notion of variables (VAR), respectively.
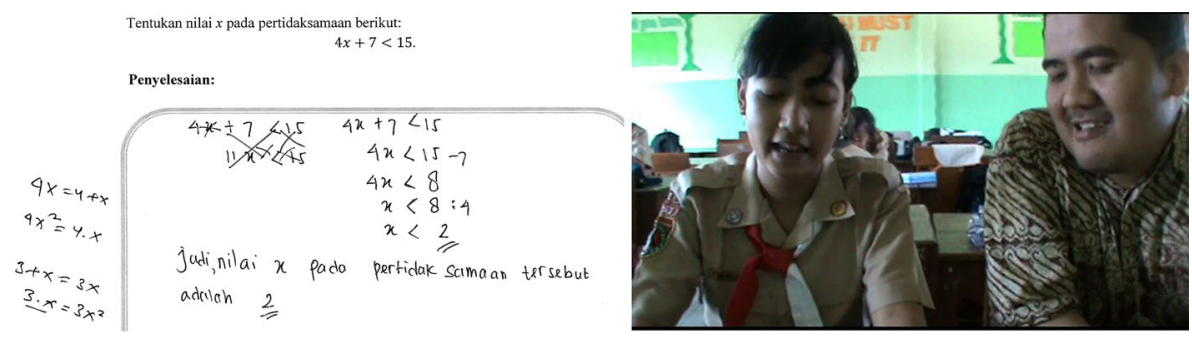

Translation:

Solve for $x: 4 x+7<15$.

Solution:

So, the value of $x$ that satisfies the inequality is 2 .

Fig. 6 A student interview on task 4 with AE and ARITH category of difficulty 
Concerning the MATH category, the frequently observed subcategories include (re)formulating equations or inequalities; interpreting mathematical concepts, patterns, and formulas; and mistranslating words, phrases, or sentences into mathematical notations, respectively. This difficulty seems to relate to horizontal mathematization and to problem solving skills which are required to solve contextual (word) algebra problems. In particular, these subcategories are in line with the first two problem solving heuristics described by Polya (1973): understanding the problem and devising a plan. In other words, the Indonesian students in this study seem to lack problem solving skills needed for initial algebra learning. As a possible explanation, this lack might result from textbooks in initial algebra education and mathematics education in elementary school which focus more on computational skills than on problem solving as is the case in the Netherlands (Kolovou et al. 2009). Therefore, we conjecture that the characteristics of mathematization as proposed by the theory of Realistic Mathematics Education and of problem solving are not so common in the learning and teaching processes in Indonesian education.

Concerning the AE category, the frequently observed subcategories include the pattern salience of algebraic expressions, the local salience of algebraic expressions, the parsing obstacle, the expected answer obstacle, and the lack of closure obstacle. In our view, this relates to students' lack of conceptual understanding in algebra, and in the notions of variables and algebraic expressions in particular (Bokhove 2011; Drijvers 2010), which might be caused by an imperfect or incomplete transition from the world of numbers to the world of symbols. Another tentative explanation is that this difficulty is caused by a teaching emphasis on calculation as opposed to understanding the meaning of an expression. In other words, the algebra that is taught might be too algorithmic and not directed enough towards understanding both how and why.

Concerning the ARITH category, the frequently observed subcategories comprise the improper use of the additive inverse property in solving an equation; improper use of the distributive property of multiplication over an addition; mistakes in carrying out addition, subtraction, multiplication, or division of algebraic expressions and numbers; and not following the rules of the order of operations. The mistakes that students made might be due to the fact that the arithmetic operations had to be carried out in the context of algebra which relates to the understanding of variables and algebraic expressions. In addition, this difficulty might also go back to elementary school with students lacking of proficiency in arithmetic calculations, understanding in using priority rules, and structure properties such as commutative and distributive laws.

Concerning the EQS category, the frequently observed subcategory concerns mistakes resulting from combining operations. This seems to be caused by students' lack of understanding of the meaning of the equal sign as algebraic equivalence (Herscovics and Linchevski 1994; Ketterlin-Geller et al. 2007; Kieran 1981; Linchevski 1995; Pillay et al. 1998).

Finally, the low frequency of the VAR category might be caused by the fact that this type of difficulty is subtle and cannot easily be identified from student work and interviews; also it is inherent to the AE and the ARITH categories.

\section{Limitations}

This study has several limitations to discuss. First, this study's data was collected during the second semester of grade VII which focused on geometry topics. This timing might have made retention of algebraic knowledge difficult for the students. Second, we recognize that 
all components of the five categories of difficulties are related each other. However, we have not analyzed these relations further in the frame of this study. The categorization itself is by no means exhaustive. It may need improvements or additional categorizations if applied to other studies. Third, regarding the analysis of student difficulties, this study addressed the rationale of why students encountered these difficulties only to a limited extent. For example, in analyzing a student mistake of $13-9 x=4 x$, we have categorized it in the AE category and as a parsing obstacle in particular (Thomas and Tall 1991) — so that the student might read 13-9 as 13-9 giving 4, and might interpret the full expression as $4 x$. We did not yet, however, address the rationale behind the difficulty. Fourth and final, for the purpose of this study, the framework which we set up has worked quite well. Still, it has only been applied to a small sample of students and to a specific case of initial algebra, and therefore needs further investigation.

\section{Implications}

The results of this study give rise several implications for algebra education in general and for algebra education in Indonesia in particular. First, the finding that mathematization is the most frequently observed category of difficulty suggests a problem associated with contextual algebra. This is in line with the TIMSS 1999 and TIMSS 2007 results in which Indonesian students had very low performances compared to international averages in solving contextual algebra tasks (Mullis et al. 2000, 2008). Do these limited mathematization skills explain Indonesia's overall low performance on studies such as TIMSS 2007 (36th position out of 48, see Mullis et al. 2008) and PISA 2009 (61st position out of 65, see OECD 2010)? We wonder if this result is general for Indonesian grade VII students.

In line with the above, the finding that mathematization and understanding algebraic expressions were the two most frequently observed categories of difficulty may suggest that initial algebra education in Indonesia should pay attention to both contextual algebra and bare algebra in a carefully balanced way. In other words, there should be equilibrium between bare and contextual algebra tasks and approaches. Contextual algebra tasks constitute not only applications of algebraic concepts, but also starting points for concept development towards more advanced algebraic concepts. Both in the bare algebra and the contextual algebra problems, the emphasis should be not only on procedural fluency, but also on understanding why the procedure works. In this way, students are expected to develop an algebraic expertise which includes both procedural skills and conceptual understanding (Bokhove 2011; Drijvers 2010).

Third, regarding the questions proposed in the Introduction section, namely why Indonesian students have low algebra scores and why they seem to experience more difficulties in learning algebra than students in other countries, a first tentative conjecture that would need further investigation is the educational factor: how is algebra taught and when is algebra introduced to Indonesian students? In spite of the curriculum revisions in the last decades (DEPDIKNAS 2006), most mathematics teaching in Indonesia still seems to be traditional (see, for instance, Johar 2010; Sembiring et al. 2008; Zulkardi 2002). In other words, there is a discrepancy between the intended and the implemented curriculum (Schmidt et al. 1997). Preserving the traditional way of teaching algebra includes, for example, a central role for the memorization of formulas. Another educational aspect might be that Indonesian students immediately start to learn algebra in a formal way, in the first semester of grade VII 
(DEPDIKNAS 2006). Therefore, the students are not prepared to learn algebra through experiences with informal algebra in elementary school. Perhaps, the difficulties students encounter in initial algebra, as we reported in this paper, are a consequence of the directly formal and traditional algebra teaching which is still prevalent in Indonesia.

Acknowledgments This study was funded by the Indonesia Ministry of Education project BERMUTU IDA CREDIT NO.4349-IND, LOAN NO.7476-IND DAN HIBAH TF090794. We would like to thank Jan van Maanen for his valuable and constructive comments and suggestions. We also thank the teachers and students for their participation, as well as the external assistant and the second coder for their contributions.

\section{Appendix 1}

1. There is a number and if 14 is added to it, then it is equal to 60 . Find the number!

2. Robert builds a step pattern using squares. Here are the stages he follows.

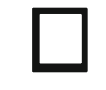

Stage 1

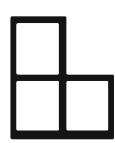

Stage 2

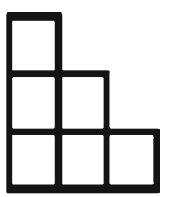

Stage 3

As you can see, he uses one square for stage 1, three squares for stage 2, and six for stage 3 . How many squares should he use for the fourth stage?

3. Solve for $x$ : $3(x-5)=2 x-7$

4. Solve for $x$ : $4 x+7<15$.

5. Amir and Tono together have Rp 30,000. If Amir's amount of money is Rp 4,000 more than Tono's, find each of their amounts.

6. The objects on the scale make it balance exactly. On the left pan, there is a $1 \mathrm{~kg}$ weight (mass) and half a brick. On the right pan, there is one brick. What is the weight (mass) of one brick?

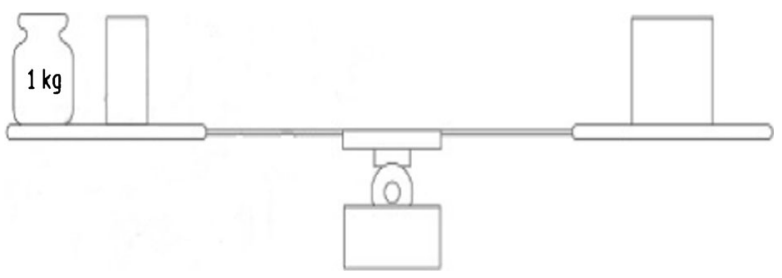
(a) $0.5 \mathrm{~kg}$
(b) $1 \mathrm{~kg}$
(c) $2 \mathrm{~kg}$
(d) $3 \mathrm{~kg}$

7. If $4(x+5)=80$, then $x=\ldots$

8. Solve for $x: 5 x+2 \geq 10-3 x$ 
9. The picture shows the footprints of a man walking.

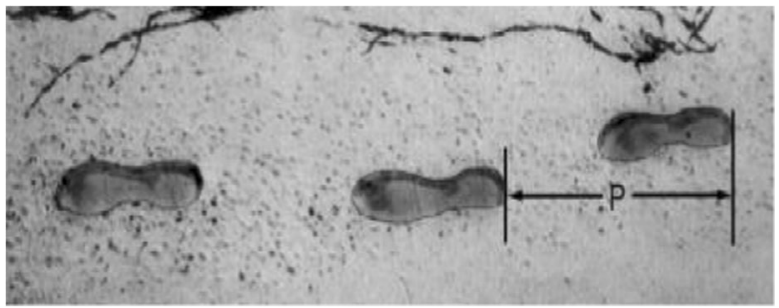

The pace length $p$ is the distance between the rear of two consecutive footprints. For men, the formula, $\frac{n}{p}=140$, gives an approximate relationship between $n$ and $p$ where, $n=$ number of steps per minute, and $p=$ pace length in meters.

(a) If the formula applies to Heiko's walking and Heiko takes 70 steps per minute, what is Heiko's pace length? Show your work.

(b) Bernard knows his pace length is $0.80 \mathrm{~m}$. The formula applies to Bernard's walking. Calculate Bernard's walking speed in meters per minute and in kilometers per hour. Show your working out.

10. If $x-y=5$ and $\frac{x}{2}=3$, what is the value of $y$ ?
(a) 6
(b) 1
(c) -1
(d) -7

11. Solve for $x: x-9=13$.

12. A cube with the edge $(x+2) \mathrm{cm}$ will be made. If the skeleton of the cube is made from a wire that is not longer than $180 \mathrm{~cm}$, find the boundaries of the edge.

13. A rectangle has length and width $(3 x-4) \mathrm{cm}$ and $(x+1) \mathrm{cm}$, respectively: (a) Write a formula for its perimeter; (b) If the perimeter of the rectangle is $34 \mathrm{~cm}$, find the area of the rectangle.

14. The sum of three consecutive positive integers is not greater than 63. Find boundaries for each of possible numbers.

15. If $L=4$ when $K=6$ and $M=24$, which of the following is true?
(a) $L=\frac{M}{K}$
(b) $L=\frac{K}{M}$
(c) $L=K M$
(d) $L=K+M$
(e) $L=M-K$

16. Solve for $x: 3 x+5=17-x$

Note: tasks 2 and 9 are taken from PISA 2006

(http://www.oecd.org/dataoecd/14/10/38709418.pdf); tasks 6, 7, 10, and 15 are taken from TIMSS 2003 (http://timss.bc.edu/PDF/T03_RELEASED_M8.pdf); other tasks are from Indonesian mathematics textbook series. 


\section{Appendix 2}

Table 11 Observed difficulties in written test: frequencies and percentages (all students, total $33 \times 4+18 \times 5=$ 222 cases)

\begin{tabular}{|c|c|c|c|c|c|c|c|c|c|c|c|c|c|c|c|c|c|c|}
\hline \multirow{2}{*}{$\begin{array}{l}\text { Cat } \\
\text { Diff }\end{array}$} & \multicolumn{16}{|c|}{ Task } & \multirow[t]{2}{*}{ Total } & \multirow[t]{2}{*}{$\%$} \\
\hline & 1 & 2 & 3 & 4 & 5 & 6 & 7 & 8 & 9 & 10 & 11 & 12 & 13 & 14 & 15 & 16 & & \\
\hline ARITH & 0 & 0 & 0 & 0 & 0 & 1 & 2 & 1 & 5 & 0 & 6 & 2 & 12 & 0 & 0 & 7 & 36 & 16 \\
\hline VAR & 0 & 0 & 0 & 2 & 0 & 0 & 1 & 0 & 0 & 0 & 0 & 0 & 0 & 0 & 0 & 2 & 5 & 2 \\
\hline $\mathrm{AE}$ & 0 & 0 & 0 & 4 & 0 & 1 & 2 & 1 & 0 & 0 & 4 & 4 & 5 & 0 & 0 & 11 & 32 & 14 \\
\hline EQS & 0 & 0 & 0 & 1 & 9 & 0 & 4 & 0 & 0 & 0 & 0 & 0 & 1 & 0 & 0 & 1 & 16 & 7 \\
\hline MATH & 0 & 0 & 0 & 0 & 23 & 7 & 2 & 0 & 4 & 0 & 0 & 9 & 14 & 10 & 0 & 1 & 70 & 32 \\
\hline
\end{tabular}

Table 12 Observed difficulties in written test of interviewed students: frequencies and percentages (total $19 \times$ $4+18 \times 5=166$ cases)

\begin{tabular}{|c|c|c|c|c|c|c|c|c|c|c|c|c|c|c|c|c|c|c|}
\hline \multirow{2}{*}{$\begin{array}{l}\text { Cat } \\
\text { Diff }\end{array}$} & \multicolumn{16}{|c|}{ Task } & \multirow[t]{2}{*}{ Total } & \multirow[t]{2}{*}{$\%$} \\
\hline & 1 & 2 & 3 & 4 & 5 & 6 & 7 & 8 & 9 & 10 & 11 & 12 & 13 & 14 & 15 & 16 & & \\
\hline ARITH & 0 & 0 & 0 & 0 & 0 & 1 & 2 & 1 & 3 & 0 & 5 & 1 & 10 & 0 & 0 & 5 & 28 & 17 \\
\hline VAR & 0 & 0 & 0 & 2 & 0 & 0 & 1 & 0 & 0 & 0 & 0 & 0 & 0 & 0 & 0 & 1 & 4 & 2 \\
\hline $\mathrm{AE}$ & 0 & 0 & 0 & 4 & 0 & 1 & 1 & 1 & 0 & 0 & 4 & 2 & 0 & 0 & 0 & 6 & 19 & 11 \\
\hline EQS & 0 & 0 & 0 & 1 & 9 & 0 & 4 & 0 & 0 & 0 & 0 & 0 & 1 & 0 & 0 & 1 & 16 & 10 \\
\hline MATH & 0 & 0 & 0 & 0 & 21 & 5 & 2 & 0 & 2 & 0 & 0 & 3 & 11 & 3 & 0 & 1 & 48 & 29 \\
\hline
\end{tabular}

Table 13 Observed difficulties in the interviews: frequencies and percentages (total $19 \times 4+18 \times 5=166$ cases)

\begin{tabular}{|c|c|c|c|c|c|c|c|c|c|c|c|c|c|c|c|c|c|c|}
\hline \multirow{2}{*}{$\begin{array}{l}\text { Cat } \\
\text { Diff }\end{array}$} & \multicolumn{16}{|c|}{ Task } & \multirow[t]{2}{*}{ Total } & \multirow[t]{2}{*}{$\%$} \\
\hline & 1 & 2 & 3 & 4 & 5 & 6 & 7 & 8 & 9 & 10 & 11 & 12 & 13 & 14 & 15 & 16 & & \\
\hline ARITH & 0 & 0 & 0 & 2 & 0 & 1 & 8 & 1 & 3 & 0 & 5 & 1 & 11 & 0 & 0 & 6 & 38 & 23 \\
\hline VAR & 0 & 0 & 0 & 3 & 0 & 0 & 8 & 0 & 0 & 0 & 3 & 0 & 0 & 0 & 0 & 6 & 20 & 12 \\
\hline $\mathrm{AE}$ & 0 & 0 & 0 & 10 & 3 & 1 & 11 & 1 & 0 & 0 & 4 & 2 & 9 & 0 & 0 & 11 & 52 & 31 \\
\hline EQS & 0 & 0 & 3 & 1 & 9 & 0 & 5 & 0 & 0 & 0 & 0 & 0 & 1 & 0 & 0 & 1 & 20 & 12 \\
\hline MATH & 0 & 2 & 1 & 0 & 25 & 5 & 5 & 0 & 2 & 1 & 0 & 4 & 13 & 3 & 0 & 1 & 62 & 37 \\
\hline
\end{tabular}




\section{References}

Adinawan, M. C., \& Sugijono, S. (2007). Matematika untuk SMP kelas VII semester 1. [Mathematics for junior secondary school grade VII semester 1.] Jakarta: Erlangga.

Arcavi, A. (1994). Symbol sense: informal sense-making in formal mathematics. For the Learning of Mathematics, 25(2), 24-35.

Arcavi, A. (2005). Developing and using symbol sense in mathematics. For the Learning of Mathematics, 14(3), 42-47.

Bokhove, C., \& Drijvers, P. (2010). Symbol sense behavior in digital activities. For the Learning of Mathematics, 30(3), 43-49.

Bokhove, C. (2011). Use of ICT for acquiring, practicing, and assessing algebraic expertise. Dissertation. Utrecht: Utrecht University.

Booth, L. R. (1988). Children's difficulties in beginning algebra. In A.F. Coxford (Ed.), The ideas of algebra, K-12(1988 Yearbook) (pp. 20-32). Reston, VA: National Council of Teachers of Mathematics

Budhi, W. S. (2007). Matematika untuk SMP kelas VII semester 1. [Mathematics for junior secondary school grade VII semester 1.] Jakarta: Erlangga.

De Lange, J. (1987). Mathematics, insight, and meaning. Utrecht: OW \& OC, Rijkuniversiteit Utrecht.

DEPDIKNAS (2006). Kurikulum tingkat satuan pendidikan sekolah menengah pertama [Curriculum of unit of education for junior secondary school.]. Jakarta: Department of National Education.

Drijvers, P. H. M. (2003). Learning algebra in a computer algebra environment: Design research on the understanding of the concept of parameter. Dissertation. Utrecht: CD-B Press.

Drijvers, P. (Ed.) (2010). Secondary algebra education. Revisiting topics and themes and exploring the unknown. Rotterdam: Sense.

Filloy, E., \& Rojano, T. (1989). Solving equations: the transition from arithmetic to algebra. For the Learning of Mathematics, 9(2), 19-25.

Freudenthal, H. (1991). Revisiting mathematics education: China lectures. Dordrecht: Kluwer Academic Publishers.

Gonzales, P., Williams, T., Jocelyn, L., Roey, S., Kastberg, D., \& Brenwald, S. (2008). Highlights From TIMSS 2007: Mathematics and Science Achievement of U.S. Fourth-and Eighth-Grade Students in an International Context (NCES 2009-001 Revised). Washington, DC: National Center for Education Statistics, Institute of Education Sciences, US Department of Education.

Herscovics, N., \& Linchevski, L. (1994). A cognitive gap between arithmetic and algebra. Educational Studies in Mathematics, 27(1), 59-78.

IEA (2003). TIMSS 2003 mathematics items: Released set eight grade. Boston: International Association for the Evaluation of Educational Achievement (IEA).

Johar, R. (2010). PMRI in Aceh. In R. Sembiring, K. Hoogland, \& M. Dolk (Eds.), A decade of PMRI in Indonesia (pp. 115-122). Bandung, Utrecht: APS International.

Jones, I., \& Pratt, D. (2012). A substituting meaning for the equal sign in arithmetic notating tasks. Journal for Research in Mathematics Education, 43(1), 2-33.

Katz, V. J. (Ed.) (2007). Algebra: Gateway to a technological future. The Mathematical Association of America

Kendal, M., \& Stacey, K. (2004). Algebra: a world of difference. In K. Stacey, H. Chick, \& M. Kendal (Eds.), The future of the teaching and learning of algebra: The 12th ICMI Study (pp. 329-346). Dordrecht: Kluwer Academic Publishers.

Ketterlin-Geller, L. R., Jungjohann, K., \& Chard, D. J. (2007). From arithmetic to algebra. Educational Leadership, 65(3), 66-71.

Kieran, C. (1981). Concepts associated with the equality symbol. Educational Studies in Mathematics, 12(3), 317-326.

Kolovou, A. (2011). Mathematical problem solving in primary school. Dissertation. Utrecht: Utrecht University.

Kolovou, A., Van den Heuvel-Panhuizen, M., \& Bakker, A. (2009). Non-routine problem solving tasks in primary school mathematics textbooks-A needle in a haystack. Mediterranean Journal for Research in Mathematics Education, 8(2), 29-66.

Landis, J. R., \& Koch, G. G. (1977). The measurement of observer agreement for categorical data. Biometrics, 33(1), 159-174.

Linchevski, L. (1995). Algebra with numbers and arithmetic with letters: a definition of pre-algebra. Journal of Mathematical Behavior, 14(1), 113-120. 
Linchevski, L., \& Herscovics, N. (1996). Crossing the cognitive gap between arithmetic and algebra: operating on the unknown in the context of equations. Educational Studies in Mathematics, 30(1), 39-65.

MacGregor, M., \& Stacey, K. (1998). Cognitive models underlying algebraic and non-algebraic solutions to unequal partition problems. Mathematics Education Research Journal, 10(2), 46-60.

Mullis, I. V. S., Martin, M. O., Gonzalez, E. J., Gregory, K. D., Garden, R. A., O’Connor, K. M., Chrostowski, S. J., \& Smith, T. A. (2000). TIMSS 1999 international mathematics report: Findings from IEA's repeat of the third international mathematics and science study at the eighth grade. Boston: International Study Center Lynch School of Education.

Mullis, I. V. S., Martin, M. O., Foy, P., in collaboration with Olson, J. F., Preuschoff, C., Erberber, E., Arora, A., \& Galia, J. (2008). TIMSS 2007 international mathematics report: Findings from IEA's trends in international mathematics and science study at the fourth and eighth grades. Boston: TIMSS \& PIRLS International Study Center

Nuharini, D., \& Wahyuni, T. (2008). Matematika konsep dan aplikasinya untuk kelas VII SMP dan MTs [Mathematics concepts and its applications for grade VII junior secondary school]. Jakarta: Book Publishing Center, Department of National Education.

OECD (2006). PISA released items-mathematics. Paris: OECD Publishing.

OECD (2010). PISA 2009 results: What students know and can do-Student performance in reading, mathematics and science (Volume 1). Retrieved March 9, 2011, from http://dx.doi.org/10.1787/ 9789264091450-en

Pillay, H., Wilss, L., \& Boulton-Lewis, G. (1998). Sequential development of algebra knowledge: a cognitive analysis. Mathematics Education Research Journal, 10(2), 87-102.

Polya, G. (1973). How to solve it: a new aspect of mathematical method (2nd ed.). Princeton: Princeton University Press.

Rosnick, P. (1981). Some misconceptions concerning the concept of variable. Are you careful defining your variables? Mathematics Teacher, 74(6), 418-420.

Saenz-Ludlow, A., \& Walgamuth, C. (1998). Third graders' interpretations of equality and the equal symbol. Educational Studies in Mathematics, 35(2), 153-187.

Schmidt, W. H., McKnight, C. C., Valverde, G. A., Houang, R. T., \& Wiley, D. E. (1997). Many visions, many aims: A cross-national investigation of curricular intentions in school mathematics (Vol. 1). Dordrecht: Kluwer.

Sembiring, R. K., Hadi, S., \& Dolk, M. (2008). Reforming mathematics learning in Indonesian classrooms through RME. ZDM, The International Journal on Mathematics Education, 40(6), 927-939.

Sfard, A. (1991). On the dual nature of mathematical conceptions: reflections on processes and objects as different sides of the same coin. Educational Studies in Mathematics, 22(1), 1-36.

Stacey, K., Chick, H., \& Kendal, M. (2004). The future of the teaching and learning of algebra: the 12th ICMI Study. Dordrecht: Kluwer Academic Publishers.

Thomas, M., \& Tall, D. (1991). Encouraging versatile thinking in algebra using the computer. Educational Studies in Mathematics, 22(2), 125-147.

Treffers, A. (1987). Three dimensions. A model of goal and theory description in mathematics instruction-The Wiskobas project. Dordrecht: Kluwer Academic Publishers.

Usiskin, Z. (1988). Conceptions of school algebra and uses of variables. In A. Coxford (Ed.), The ideas of algebra, K-12 (pp. 8-19). Reston: National Council of Teachers of Mathematics.

Van Amerom, B. A. (2002). Reinvention of early algebra: developmental research on the transition from arithmetic to algebra. Dissertation. Utrecht: CD-B Press.

Van Amerom, B. A. (2003). Focusing on informal strategies when linking arithmetic to early algebra. Educational Studies in Mathematics, 54(1), 63-75.

Van den Heuvel-Panhuizen, M. (2000). Mathematics education in the Netherlands: a guided tour. Freudenthal Institute Cd-rom for ICME9. Utrecht: Utrecht University.

Van den Heuvel-Panhuizen, M. (2003). The didactical use of models in realistic mathematics education: an example from a longitudinal trajectory on percentage. Educational Studies in Mathematics, 54(1), 9-35.

Wagiyo, A., Surati, F., \& Supradiarini, I. (2008). Pegangan belajar matematika untuk SMP/MTs kelas VII. [Handbook of learning mathematics for junior secondary school grade VII.]. Jakarta: Book Publishing Center, Department of National Education.

Warren, E. (2003). The role of arithmetic structure in the transition from arithmetic to algebra. Mathematics Education Research Journal, 15(2), 122-137.

Watson, A. (2009). Algebraic reasoning. Key understanding in mathematics learning. University of Oxford: Nuffield Foundation.

Zulkardi (2002). Developing a learning environment on realistic mathematics education for Indonesian student teachers. Dissertation. Enschede: University of Twente. 